\title{
Features of Selecting and Structuring Foreign Language Teaching Content in Terms of International Component
}

\author{
Elena Valeryevna Grigoryeva ${ }^{1}$, Ravilya Minnekhanovna Zakirova ${ }^{2}$, Galina Vasilyevna Solovyeva ${ }^{2}$, Lyudmila \\ Semenovna Balashova ${ }^{2}$, Almira Kadyrovna Garayeva ${ }^{1} \&$ Timur Ravilevich Usmanov ${ }^{3}$ \\ ${ }^{1}$ Kazan (Volga region) Federal University, Russia \\ ${ }^{2}$ Yelabuga Institute of Kazan (Volga region) Federal University, Russia \\ ${ }^{3 .}$ Kazan Cooperative Institute (Branch) of the Russian University of Cooperation, Russia \\ Correspondence: Elena Valeryevna Grigoryeva, Kazan (Volga region) Federal University, Kremlyovskaya Street, \\ 18,420008, Kazan, Russia. E-mail: amalia565@mail.ru
}

Received: October 1, 2014 Accepted: November 14, 2014 Online Published: December 2, 2014

doi:10.5539/ass.v11n1p380 URL: http://dx.doi.org/10.5539/ass.v11n1p380

\begin{abstract}
Analysis of Russian curricula and textbooks for foreign language demonstrates that most of them don't meet the requirements of education internationalization. So, the purpose of this paper is to reveal the features of foreign language teaching content selection and structuring based on the international component. The paper reveals the features of foreign language teaching content for students in the context of education internationalization which includes acquisition of knowledge that interprets the main humanity values, touches upon global problems of the modern multicultural world, cross-cultural and socio-cultural knowledge; shaping skills needed for cross-cultural communication, skills to carry out cross-cultural analysis of the interaction ways with the world around as well as formation of transcultural experience. The materials of this paper may be useful for faculty members of vocational training institutions when selecting and structuring the language teaching content as well as for further education courses of foreign language teachers.
\end{abstract}

Keywords: content, foreign language, selection and structuring, international component, internationalization of education, students

\section{Introduction}

Extension and qualitative changes of international cooperation, Russia's integration into the Bologna process, its inclusion into global market made foreign language not a mere means of communication in foreign professional environment but a really popular means to improve the intellectual and practical activity of specialists (Bulgakova and Sosnov, 2003; Oleinikova, 2003; Grigoryeva, 2007). The state and society began to feel the urgent need for people speaking foreign languages, practically and often at a high professional level. Undoubtedly, modern society has become increasingly aware that knowledge of foreign language and culture of the country of the language gives indispensible advantages: more chances to be integrated in a rapidly changing society with a market economy, to be better employed, to study the culture of other nations to the utmost, to conceive the global problems. Practical foreign language fluency began to be perceived as a significant achievement of an individual. Cross-cultural communicative competence gains importance for young people as a means of interaction between people, a way of communication processes and internationalization of achievements in culture, science, economy and technology, a means of introduction to the national culture which significantly affects the cultural and educational level of an individual and his/her values. Under the internationalization of world labor market cross-cultural communicative competence of Russian students adds to the prestige of the vocational training received, and language resources enhance the competitiveness of native specialists and expand their professional and socio-cultural horizons.

Internationalization is studied by many researchers who consider the problems of international education. Internationalization of education is a cultural phenomenon that allows to reveal the inner directions of the modern education development in the world with regard to culture and traditions, and therefore becomes an important component of the countries' educational policy. This is the expansion of access to higher education, the universalization of knowledge, the development of international quality standards, the strengthening the 
innovative nature of higher education and the expansion and strengthening of international cooperation (Garrahan, 2012).

The remarkable advantages of higher education internationalization include the possibility of getting the international education for the student who has no need to leave his/her own university because students undoubtedly benefit from the prospects to study with representatives of other countries at the host university (Usher, 2009).

Integration of Russia into economic and educational community, extending diversified contacts with European countries and USA, changing status of foreign language in the modern world propose renovation of the language teaching content in the context of education internationalization. It gives an opportunity for students to get education corresponding to international standards inside their own higher education institution, increase attractiveness of higher education institution for foreign students, and make possible comparison and correlation of education results at different levels (Gorski, 2009).

The processes of education internationalization require introducing new standards in the field of language education, developing appropriate curricula, substantiating the selection principles of language teaching content taking into account both national and foreign experience in this field. At the same time we are not satisfied with our present curricula. The language competence level of students of non-linguistic specialties is often focused on the passive ability to read and translate. Students learn grammar and use mainly special texts. This, of course, helps them find their way in future profession but communication and competent expressing their thoughts and ideas in writing form remain a problem. It seems that the processes of globalization we are all involved require that students of non-linguistic specialties get a stronger training in foreign languages than it happens now.

\section{Methodological Framework}

Selection and structuring of foreign language teaching content aimed at the formation and development of students' cross-cultural communicative competence should be guided by the principles which primarily take into account the processes of education internationalization, meet the needs, capabilities and abilities of students and could be a reliable basis for the further advancement of knowledge, formation and development of competences in modern dynamic society.

We include the following selection principles of language teaching content in relation to the problem of this study:

- principle of person-oriented approach which involves correspondence of teaching material to the real interests and abilities of students;

- principle of communicative orientation which determines the selection and organizing of linguistic material, specification of spheres and communicative situations, communicative skills;

- principle of professional orientation which implies a clear design of language material and meaningful structure of the content in whole which is agreed between allied special disciplines;

- principle of integration which involves the creation of integrated curricula;

- principle of consideration of linguistic world-image dynamics which involves considering a complex of world concepts, modern trends in language education and changes in its content;

- principle of multiculture according to which language teaching content should reflect certain elements of different ethnic cultures to promote a sense of respect for other peoples;

- principle of consideration of native language requires different connections between foreign and native languages for comparison and developing a system of equivalents;

- principle of internationalization involving students' knowledge and skills internationalization and the formation of their cultural skills.

If the principles of selecting language teaching content define an ideal model of its content needed and sufficient to achieve the objective, the principles of designing language teaching content reflect its didactic organization.

We refer the following binary principles to these:

- principle of integrity and phasing which assumes, on the one hand, designing language teaching content as an integral process and, on the other hand, obligation of running all design stages separately;

- principle of discreteness and continuity based, on the one hand, on the discontinuity of the designing process and achievement of its definite results according to the situation and, at the same time, assuming the continuity 
of the project activities to achieve the result of the designing according to the changing requirements of language teaching content in the context of education internationalization;

- principle of predictability and reality which is characterized by the ability to predict and model the result of design, to assess its practical significance and implement activities for its further adjustment and, at the same time, to provide appropriate warrants to obtain project objectives;

- principle of innovativeness and traditionalism which includes, on the one hand, the need to a permanent innovation of language teaching content in accordance with the latest developments of educational theory and practice in this area, and, on the other hand, takes into account the existing conceptual ideas in the field of teaching content designing;

- principle of dynamism and stability involves the designing of such language teaching content that would provide an opportunity for its rapid and easy changes in accordance with the emerging needs of an individual, the state and society that at the same time doesn't imply opposition to the further development of the design process but ensures stable condition and allows it to be effectively developed in terms of external and internal impact while keeping its structure and basic quality parameters (Grigoryeva, 2008).

The above mentioned principles of designing language teaching content are interdependent and are complemented by each other. If the principles indicate the general direction of language teaching content designing, criteria of principles manage the procedure of its designing which is made up of teaching material structuring and its sequence. Selection criteria for one or another principle of designing language teaching content are: a) instrumentality that is knowing how to use the principle; b) universalism that is relatedness of the principle to the whole process of designing language teaching content; $c$ ) independence of principles, i.e. they are not substituted and unabsorbable by other principles; d) sufficiency of the whole complex of principles which provides the integrity and usefulness of the designing process of language teaching content at the economic faculties of higher education institutions in the context of education internationalization.

\section{Results}

The objective of foreign language teaching content is the formation and development of students' cross-cultural communicative competence to meet the challenges of academic, professional and socio-cultural mobility in the context of education internationalization.

The learning objectives of language teaching content are:

- strengthening students' motivation to study topics affecting global problems of mankind, interdependence among nations and peoples in the context of the dialogue of cultures, upbringing in the sense of peace as well as topics which include financial - economic terminology and business-oriented vocabulary in the context of professionally-oriented international communication;

- orientation of foreign language knowledge, skills and competences at cross-cultural communication in the process of future professional activity in the context of education internationalization;

- formation and development of student skills to work in a team and independently search for relevant information and its creative use in professional activity in the international labor market as well as the formation of tolerance and self-education competence;

- ensuring the strength of the above knowledge, skills and competences through an increase in speech practice both in terms of the reception (that is reading and especially listening) and reproducing (speaking and creative writing) in the context of education internationalization (Grigoryeva, 2006).

Unlike traditional one, language teaching content which we developed presented:

1) topics interpreting the core values of human civilization in the context of education internationalization: living standards, values and culture, spirituality and morality, freedom and responsibility and so on;

2) topics touching upon the global problems of the modern multicultural world, in particular, problems of racism, discrimination, ethnocentrism, national extremism, protection of minority rights as well as environmental, economic, gender, demographic problems and possible ways of their non-violent resolution, and reflecting the interdependence between nations and peoples, irenic and human rights education by means of languages and cultures studied;

3) interdisciplinary introduction to socio-cultural "Portrait of Europe" and other countries in the context of the dialogue of cultures including the content of cross-cultural and socio-cultural knowledge: knowledge of geography, ethnography, economics and politics; knowledge of ethics and cultural realities, communication 
standards between representatives of different generations, sexes, community groups; knowledge of the linguistic means for expressing certain rituals adopted in this society; knowledge of background, connotative and non-equivalent lexis; knowledge of socio-cultural stereotypes of verbal behavior in a foreign language needed for social interaction of communicants in the context of education internationalization;

4) international topics operating in cross-cultural communication of specialists in economics: "Foreign Enterprise (legal status, type, structure)", "International marketing and management", "International corporate finance", "Foreign trade contract", "Export-Import", "Modern means of communication (fax, phone, Internet)", "International business correspondence" and so on;

5) topics functioning in scientific field of the specialists' professional activities in terms of promoting international cooperation, that is: "Plans for scientific research in international economics", "Scientific cooperation/ scientific experiment", "Latest advances in the field of economics", "Modern trends of economic science and modern technology", "Organizing international conferences/ symposiums/ seminars (program/ performance report/ procedure for opening and closing/ discussion)", "Discussion of the report/ of the scientific report/ of the plan/ thesis research" (Grigoryeva, 2006).

At the stage of the experiment formation active methods and forms were used allowing to realize the language teaching content due to internationalization of education, that is: modeling texts, sharing info, jigsaw activities / information gap activities, communication games, business games, role games, problem solving, creative tasks, close-text activity, situation modeling and forecasting, selection of language means for solving communicative problem, constructing the text having the key phrases, ranking, language tests diary, negotiations, presentation, reporting back, free discussion, scenario, interview, discussion, brainstorming, project works, on-line conference and so on.

At this stage of the experiment teaching material was regarded as the growing complexity of the fundamental provisions allowing to build the integrity of the situations where every situation is an evolution of the previous one. Initially, students' skills of cross-cultural communicative competence naturally evolved into new ones or improved in terms of education internationalization. Students acquired the methods of educational activities, the ability to independently master foreign language and to manage this process.

Control phase of the experiment revealed changes in the level of students' cross-cultural communicative competence formation in economics considering education internationalization before and after the forming stage of the experiment as well as results comparison of experimental and control groups identified differences of the parameters investigated in favor of the experimental group.

Table 1. Breakdown of students by development levels of cross-cultural communicative competence

\begin{tabular}{|c|c|c|c|c|}
\hline \multirow{2}{*}{ Levels } & \multicolumn{2}{|c|}{ Control group (94 persons) } & \multicolumn{2}{|c|}{ Experimental group (107 persons) } \\
\hline & before & after & before & after \\
\hline Low & $6 \%$ & $5 \%$ & $6,5 \%$ & $0 \%$ \\
\hline Sufficient & $53 \%$ & $48 \%$ & $51,5 \%$ & $20 \%$ \\
\hline Acceptable & $29 \%$ & $36 \%$ & $31 \%$ & $63,5 \%$ \\
\hline High & $12 \%$ & $11 \%$ & $11 \%$ & $16,5 \%$ \\
\hline
\end{tabular}

Analysis of the results presented in Table 1 shows the trend of student's experimental group to transit from a low to an acceptable level, from an acceptable to sufficient and high levels of cross-cultural communicative competence formation. No significant changes are occurred in the control group.

Thus, the experimental work carried out stated the increase in the students' level of formation of cross-cultural communicative competence within the research problem that generally confirms the effectiveness of the pedagogical conditions proposed for designing and implementing the language teaching content for students of economics in the context of education internationalization.

\section{Discussions}

Modern pedegogics has accumulated the necessary complex of knowledge which can be a prerequisite for the solution of the research problem: the problems and prospects of higher education internationalization are revealed (Verbitskaya, 1999; Dibrova, 2004; Dzhurinsky, 2002); foreign language status positions in higher education system in the expanding socio-communicative processes in the world, problematics of educational know-how and teaching methods used in teaching and learning activities are identified (Bim, 2005; Kitaygorodskaya, 1992; Leontiev, 1999; Passov, 1999). 
The thesis researches discuss the various problems of language education, in particular: professionally-oriented foreign language teaching at non-language higher education institution (Alekseeva, 2002; Lesokhina, 1995; Maximova, 2007; Mertsalova, 2000; Mitrukhina, 2005; Kharisova, 2001); material selection and methodological organization of the educational process while teaching different types of foreign language behavior for non-philologers (Ozerova, 1998; Mikhalkina, 1994; Do Kong Chong, 2001); designing of foreign language teaching system at non-language higher education institution (Bulatova, 1999; Ephremzeva, 2000; Khanzeva, 2000); language training of students in economics (Baukina, 1999; Buzina, 2000; Levina, 2001; Samoilova, 2004; Khaustov, 2001).

However, the study and theoretical analysis of psychological and pedagogical researches demonstrated that the problem of designing and implementing the language teaching content of students at the economic faculties of higher education institutions in the context of education internationalization is an understudied field of scientific knowledge.

\section{Conclusion}

Thus, language teaching content considering international component which we developed includes the following topics: interpreting the core values of human civilization in the context of education internationalization; topics touching upon the global problems of the modern multicultural world, in particular, problems of racism, discrimination, ethnocentrism, national extremism, protection of minority rights as well as environmental, economic, gender, demographic problems and possible ways of their non-violent resolution, and reflecting the interdependence between nations and peoples, irenic and human rights education by means of languages and cultures studied; interdisciplinary introduction to socio-cultural "Portrait of Europe" and other countries in the context of the dialogue of cultures including the content of cross-cultural and socio-cultural knowledge as well as knowledge of ethics and cultural realities, communication standards between representatives of different generations, sexes, community groups; knowledge of the linguistic means for expressing certain rituals adopted in this society; knowledge of background, connotative and non-equivalent lexis; knowledge of socio-cultural stereotypes of verbal behavior in a foreign language needed for social interaction of communicants in the context of education internationalization; international topics operating in cross-cultural communication of specialists in economics; topics functioning in scientific field of professional activity.

The content of the considered problem is not exhausted by the study. Further researches can be devoted to optimal mechanisms identification for economic profile future specialists foreign language training quality monitoring in education internationalization conditions.

\section{References}

Alekseeva, L. E. (2002). Optimization of the process of training the is professional-oriented dialogue of students of the Faculty of International Relations (PhD Thesis). St. Petersburg.

Baukina, S. A. (1999). Education communicative tactics of business communication students in economics $(\mathrm{PhD}$ Thesis). Moscow.

Bim, I. L. (2005). Modernization of the structure and content of language education. Foreign languages in school, 8, 2-6.

Bulatova, D. V. (1999). Theoretical Foundations course in a foreign language not language high school ( $\mathrm{PhD}$ Thesis, p. 521). Moscow.

Bulgakov, N. G., \& Sosnov, N. G. (2003). Does the train to Bologna? Paid education, 2, 15-18.

Buzina, Y. N. (2000). Education, the English texts in economics (PhD Thesis, p. 142). Moscow.

Cheung, D. K. (2001). Selection and methodical organization of material on training foreign students-economists reading and written business formalities in business (PhD Thesis). Moscow.

Dibrova, M. I., \& Kabanova N. M. (2004). Changes in the structure of the university as a result of the internationalization of education. University Management: Practice and Analysis, 2(31), 58-60.

Dzhurinsky, A. N. (2002). Internationalization of Higher Education: Trends and Challenges. Journal of Higher Education, 9, 44-49.

Efremtseva, T. N. (2000). Designing the content of foreign language teaching in the process of continuous professional tourism education ( $\mathrm{PhD}$ Thesis). Moscow.

Garrahan, P. (2012). Strategies for Internationalization in Higher Education: The UK and China Experience. 
Sheffield Hallam University. Retrieved from https://staff.shu.ac.uk/exec/philipgarrahan.asp

Gorski, P. C. (2009). Intercultural education as social justice. Intercultural Education, 20(2), 87-90.

Grigoryeva, E. V. (2006a). International Business Issues: Textbook for high school students (p. 36). KSFEI Press.

Grigoryeva, E. V. (2006b). Program of discipline "English" for specialties 521500 "Management" and 521600 "Economics" (p. 31). KSFEI Press, Kazan.

Grigoryeva, E. V. (2007). The nature and content of the main components of learning a foreign language in high school in the internationalization of education. Kazan Pedagogical Journal, 5, 10-15.

Grigoryeva, E. V. (2008). Design and implementation of the content of foreign language teaching in higher education, taking into account the internationalization of education (for example, economics departments) (PhD Thesis, p. 204). Kazan.

Hantseva, G. G. (2000). Formation of professional orientation of students in the process of learning a foreign language (on the basis of a technical college) ( $\mathrm{PhD}$ Thesis). Rubtsovsk.

Kharisova, G. G. (2001). Language teaching business communication language high schools students in the regional context (based on universities Nizhnevartovsk) (PhD Thesis). Tomsk.

Khaustov, O. N. (2001). Modeling of the vocational training business English language specialists in economics in terms of the higher school ( $\mathrm{PhD}$ Thesis). Tambov.

Kitaygorodskaya, G. A. (1992). Intensive training in foreign languages Cams: Theory and Practice (p. 254). Russian Language Press, Moscow.

Leontyev, A. A. (1999). Fundamentals of psycholinguistics (p. 287). Meaning Press, Moscow.

Lesokhina, T. B. (1995). Features learning foreign language scientific and technical communication at the university (in the English language) ( $\mathrm{PhD}$ Thesis). Moscow.

Levina, E. V. (2001). Formation of linguistic and cognitive economic thesaurus trainees (PhD Thesis). Moscow.

Maximova, E. V. (2007). Formation of core competencies ssuz students in the study of foreign languages $(\mathrm{PhD}$ Thesis). Kazan.

Mertsalova, S. L. (2000). Methodology of teaching reading authentic texts "Technology products catering" (based on the English. Language) (PhD Thesis). Moscow.

Mikhalkina, I. V. (1994). Communicative and linguistic content of teaching professional communication specialists in the field of foreign relations ( $\mathrm{PhD}$ Thesis). Moscow,.

Mitryuhina, M. S. (2005). Continuity formation of communicative culture in the teaching of a foreign language (in the "school - ssuz - high school") (PhD Thesis). Kazan.

Oleinikova, O. N. (2003). European processes in the development of vocational education and training. Vocational Education, 11, 48-50.

Ozerov, M. V. (1998). Contents professionally-directed learning a foreign language in not language high school and its organization in the textbook (advanced stage, French) ( $\mathrm{PhD}$ Thesis, p. 226). Moscow.

Passov, E. I. (1999). Communicative foreign language education. The concept of personality development in the dialogue of cultures (p. 68). Lipetsk.

Samoilova, E. S. (2004). Learning a foreign language as a factor in the formation of professional competence economist ( $\mathrm{PhD}$ Thesis). Kazan.

Usher, A. (2009). Ten Years Back and Ten Years Forward: Developments and Trends in Higher Education in Europe Region (p. 44). Bucharest: CEPES Press.

Verbitskaya, L. A. (1999). Program "Integration" and the task of the Federal Research University. Herald of high school, 11, 21-23.

\section{Copyrights}

Copyright for this article is retained by the author(s), with first publication rights granted to the journal.

This is an open-access article distributed under the terms and conditions of the Creative Commons Attribution license (http://creativecommons.org/licenses/by/3.0/). 